\title{
A formação docente na visão de professores formadores
}

\author{
Camila Gimenes ${ }^{1}$
}

Odisséa Boaventura de Oliveira ${ }^{2}$

\section{Resumo}

Neste estudo, tem-se como objetivo investigar a concepção de formação inicial de treze professores formadores de um curso de licenciatura em Ciências Biológicas de uma universidade pública a partir de seus discursos, que foram analisados segundo três categorias epistemológicas, inspiradas em Vázquez (1977): atividade teórica, atividade prática e práxis. Conclui-se que nos discursos investigados a epistemologia da atividade teórica é a tendência dominante entre os docentes responsáveis por disciplinas específicas. Para os professores de disciplinas pedagógicas, observa-se que a tendência mais influente é a epistemologia da atividade prática. Entretanto, ambas representam uma concepção instrumental de formação docente, de modo que teoria e prática estão epistemologicamente separadas nessa formação, no próprio conceito de formação de professores, com consequente negação da práxis.

Palavras-Chave: formação docente; prática; teoria. 


\title{
The teacher training in the view of teachers trainers
}

\begin{abstract}
The aim of this research is to investigate the conception of teacher education in interviews with thirteen teachers educators of Biology and Sciences teacher education progam at a public university. The interviews were analyzed by the framework of three epistemological categories, inspired by the work of Vázquez (1977): theoretical activity, practical activity and praxis. The speeches analyzed point to the epistemology of theoretical activity as the dominant trend among the professors responsible for specific subjects. For teachers teaching pedagogical subjects, we observed that the trend predominant is epistemology of practical activity. However, this both epistemologies represent an instrumental conception of teacher education, so theory and practice are epistemologically separate in this formation, in the very concept of teacher education, with consequent denial of praxis.
\end{abstract}

Keywords: teacher training; practice; theory.

\section{Introdução}

A formação inicial docente vem passando por reformas direcionadas pela promulgação das Diretrizes Curriculares Nacionais (DCN) para a Formação de Professores da Educação Básica e das DCN específicas para cada curso superior. Esses documentos foram publicados com o objetivo "explícito" de superar a dicotomia entre teoria e prática na formação docente (entre outros objetivos) e têm influenciado as reformulações de projetos pedagógicos dos cursos de licenciatura, em especial com a Resolução n 02, de 19 de fevereiro de 2002 (BRASIL, 2002), que determina a carga horária de "Prática como elemento curricular" e de "Estágio supervisionado".

A esses documentos, segue-se uma ampliação sem precedentes do acesso dos setores majoritários da população ao Ensino Superior. 
Nesse contexto de expansão do nível de formação para a docência e do acesso a essa formação, colocamos como questão central a finalidade e a concepção dessas ações e como elas rebatem no vivido pelos agentes envolvidos nos contextos educacionais.

Diante desse quadro de modificações nas políticas de formação docente, incluindo a reforma curricular dos cursos de licenciatura, que se alinha a uma tendência das políticas públicas para a educação a nível nacional, questionamos: qual a concepção de formação inicial dos professores formadores? Qual o conceito de prática e de teoria aí presente? Como esses docentes enfrentam a histórica dicotomia entre teoria e prática na formação docente?

Estimulados por esse contexto de mudanças, analisamos um curso de licenciatura em Ciências Biológicas a partir de entrevista com treze professores responsáveis por disciplinas de conhecimento específico biológico e de conhecimento específico do campo educacional, com o objetivo de compreender a fundamentação epistemológica da formação docente que embasa seus dizeres. Procuramos olhar para o espaço que a teoria e a prática ocupam em seus discursos, a fim de estabelecer relações entre a formação docente e a imagem do futuro professor que os entrevistados constroem em seus dizeres.

Buscamos analisar o que os professores formadores destacam sobre relação teoria-prática em função do que chamamos de fundamentação epistemológica, ou seja, quanto às relações "de" saber e "com" o saber que são estabelecidas em suas disciplinas. Para elaborarmos as tendências epistemológicas, nos inspiramos em Vázquez (1977), fazendo um diálogo com outros autores, que é apresentado a seguir.

\section{Categorias da formação docente}

Consideramos três categorias epistemológicas que fundamentam o processo de formação docente tendo Vázquez (1977) como referencial: epistemologia da atividade teórica, epistemologia da atividade prática e epistemologia da práxis. Cada epistemologia proporciona a construção de processos formativos específicos, pois propõe lógicas de ação diferentes. 


\subsection{Epistemologia da atividade teórica}

A formação docente está fundamentada na epistemologia da atividade teórica quando a teoria é a base da relação "com" o saber e "de" saber que se estabelece no processo formativo.

A atividade teórica caracteriza-se pela produção de objetivos e de conhecimento e as transformações por ela realizadas são transformações ideais, ou seja, das ideias sobre o mundo, mas não do mundo mesmo.

Seu objeto ou matéria-prima são as sensações ou percepções - ou seja, objetos psíquicos que só têm uma existência subjetiva - ou os conceitos, teorias, representações ou hipóteses que têm uma existência ideal. A finalidade imediata da atividade teórica é elaborar ou transformar idealmente, e não realmente, essa matéria prima, para obter, como produtos, teorias que expliquem uma realidade presente, ou modelos que prefigurem idealmente uma realidade futura. A atividade teórica proporciona um conhecimento indispensável para transformar a realidade, ou traça finalidades que antecipam idealmente sua transformação, mas num e noutro caso fica intacta a realidade efetiva. (VÁZQUEZ, 1977, p. 203)

Ao instrumentalizar para a compreensão dos contextos, a teoria coloca-se como forma de "lançar a dúvida de forma sistematizada, de modo que o entendimento que se tem da realidade educacional esteja alicerçado em argumentos conceituais", teorizar é apresentar a dúvida (PACHECO, 2011, p. 280).

Paulo Freire (2011) discute a respeito do fato de a teoria ser identificada como oposição à realidade, quando, na verdade, ela implica inserção na realidade, um contato analítico com o existente, para comprová-lo, para vivê-lo e vivê-lo plenamente, praticamente. Essa distorção não é sem propósito, traz consigo o interesse de não comunicar o verdadeiro papel da teoria.

A prática profissional fica reduzida à aplicação de meios disponíveis a fins predeterminados e bem definidos, desconsiderando-se o contexto mais amplo no qual o ensino ocorre e no qual cobra sentido. Nessa concepção, há hierarquia de subordinação entre teoria e prática, que é refletida na estrutura da formação docente. Geralmente, o período de práticas se encontra no final do curso e seu estatuto formativo costuma 
estar mal definido, relegado muitas vezes à mera experiência, dado seu caráter ambíguo e de segundo plano (CONTRERAS, 2002).

\subsection{Epistemologia da atividade prática}

A atividade prática, para Vázquez (1977), é real, objetiva ou material. $\mathrm{O}$ sujeito age sobre uma matéria que existe independente de sua consciência. Nesse mundo do homem prático, as coisas não apenas são e existem em si, como também são e existem, em especial, por sua significação prática, na medida em que satisfazem necessidades "imediatas" de sua vida cotidiana. Assim, tem-se o prático reduzido a apenas uma dimensão, a do prático-utilitário. Nesse caso, a educação é entendida como algo prioritariamente de natureza prática, de modo a reduzir o conhecimento à "praticidade" dos contextos, sem que se discutam formas culturais e sociais de pertença (PACHECO, 2011).

Assim, a epistemologia da atividade prática apresenta a prática docente como elemento articulador do processo formativo. "A prática adquire o papel central de todo o currículo, assumindo-se como o lugar de aprendizagem e de construção do pensamento prático do professor" (GÓMEZ, 1992, p. 110, grifos do autor). Essa epistemologia formativa engloba os conceitos de racionalidade prática e professor reflexivo, que se caracterizam pela oposição à racionalidade técnica. Destaca-se a reflexão "sobre a" e "na" prática docente, o conhecimento-na-ação e a construção de competências profissionais, sendo estas reguladas por meio de avaliação institucional.

É evidente os avanços na compreensão do processo educativo advindos com o "programa reflexivo", como a recusa do professor meramente técnico, a afirmação da prática docente como uma ação consciente e deliberada, a correspondência entre teoria e prática nas ações cotidianas, a aceitação da existência de pressupostos imperativos e valorativos na atuação e nas decisões profissionais, embora a prática por si só não possibilite a superação de todas essas demandas (LIBÂNEO, 2010).

Porém, quando se defende o modelo do professor reflexivo, não se discute o conteúdo sobre o qual esse profissional reflete, nem a reflexão 
sobre as circunstâncias concretas de sua prática. Segundo Pimenta (2010a, p. 46)

também se observa uma tendência em proceder a tecnização da reflexão, a partir de sua operacionalização em inúmeras competências a serem desenvolvidas no processo formativo inicial e em serviço, colocando as bases para uma avaliação da atividade dos professores, a partir delas, individualmente consideradas. [...] Também presentes na desqualificação dos professores com a transformação de seus saberes em saberes-fazeres, diretamente ligados à operacionalização do ensino e com a definição de novas identidades dos docentes transformando-os em tutores e monitores da aprendizagem.

Desse modo, entende-se a formação numa perspectiva instrumental e pragmática, com a desvalorização da teoria das ciências da educação e primado da prática profissional, num movimento pela profissionalização docente. Nessa perspectiva, o valor do conhecimento se dá pela sua utilidade imediata na prática docente, que é compreendida como elemento articulador do processo de formação do professor (KUENZER, 2008).

\subsection{Epistemologia da práxis}

“A práxis é a categoria central da filosofia que se concebe ela mesma não só como interpretação do mundo, mas também como guia de sua transformação" (VÁZQUEZ, 1977, p. 5). A práxis, como atitude humana transformadora da natureza e da sociedade, é atividade teórica e prática; "prática, na medida em que a teoria, como guia da ação, molda a atividade do homem, particularmente a atividade revolucionária; teórica, na medida em que essa relação é consciente" (VÁZQUEZ, 1977, p. 117).

Nessa epistemologia, teoria e prática relacionam-se de modo indissolúvel. A prática é fundamento, finalidade e critério de verdade da teoria. A primazia da prática sobre a teoria, longe de implicar contradição ou dualidade, pressupõe íntima vinculação a ela (VÁZQUEZ, 1977). Para Kuenzer (2008, p. 17), a partir da práxis, “entende-se a prática sempre como ponto de partida e ponto de chegada do trabalho intelectual, através do trabalho educativo, que integra estas duas dimensões".

Para a práxis, a reflexão sobre a prática docente também ocupa 
um lugar de destaque no processo de constituição do professor, porém essa reflexão dialoga com a teoria produzida pela pesquisa em educação, tendo como objetivo final que a ação docente contribua com a transformação da realidade social, de forma a torná-la mais justa e igualitária. A teoria permite a interpretação e análise da prática, além da observação imediata, compreendendo as relações, as finalidades, as estruturas internas entre essa prática e o contexto no qual se insere.

Considerando-se o contexto e a organização socioeconômica em que a formação docente se efetiva, a divisão do trabalho intelectual do trabalho manual é estratégica para a manutenção dos meios de dominação. Ou seja, tal dicotomia entre teoria e prática é intrínseca ao modelo adotado e, no entanto, opondo-se a essa dicotomia, a educação apresenta-se como possibilidade de construção de subjetividades comprometidas com a transformação das relações sociais (KUENZER, 2007).

\section{Procedimentos metodológicos}

Utilizamos a abordagem qualitativa como metodologia para o desenvolvimento desse estudo, visto que a pesquisa dessa natureza busca incorporar a questão do significado e da intencionalidade como inerentes aos sujeitos e como suas construções (MINAYO, 2000). Analisamos aqui duas questões de uma entrevista semiestruturada realizada com treze professores do Curso de Ciências Biológicas, responsáveis por disciplinas específicas ou pedagógicas ${ }^{3}$.

Para selecionar quais professores seriam convidados a participar da entrevista, foi aplicado um questionário às turmas de formandos do curso em 2008 e 2009, que interrogava a respeito dos docentes mais marcantes em sua formação como professor. Foi solicitado que citassem três nomes e a justificativa da sua escolha, podendo ser professores lembrados por aspectos positivos ou negativos, responsáveis por disciplinas específicas ou pedagógicas.

3 Essa divisão não é absoluta, pois as disciplinas ditas específicas são também pedagógicas; assim como as disciplinas pedagógicas possuem também conhecimentos específicos. Utilizamos essa nomenclatura para distinguir as disciplinas ofertadas pelo Setor de Educação da universidade em que esse curso é ofertado - disciplinas pedagógicas - das disciplinas ofertadas pelo Setor de Ciências Biológicas -disciplinas específicas. 
Foram citados no total os nomes de 55 professores. Destes, 43 foram lembrados positivamente, oito negativamente, dois foram lembrados ora por motivos positivos, ora por negativos e dois não tiveram justificadas suas atuações na formação. Os aspectos positivos mais destacados pelos respondentes foram: a didática do professor; o conhecimento da disciplina que leciona; o uso de estratégias ou metodologias diferenciadas; a consideração pelo aluno (ser acessível a ele ou respeitálo); a manifestação de vontade por ensinar; aulas interessantes, interativas ou dinâmicas; características pessoais (calma ou paciência ou humildade); preocupação com formação crítica, reflexiva e intelectual do aluno; a abordagem do conteúdo (evolutiva, cotidiana, epistemológica ou atual).

Em relação aos aspectos negativos, destacaram-se: a inadequação da avaliação; o professor servir como exemplo a não ser seguido; a falta de didática; ser um péssimo professor (sem justificar o porquê).

Os nomes de professores citados por quatro ou mais alunos foram escolhidos para participarem das entrevistas realizadas entre outubro e dezembro de 2008 e entre dezembro de 2009 e maio de 2010, que tiveram duração média de trinta minutos e foram gravadas em áudio.

A entrevista semiestruturada realizada com esses treze professores foi organizada em quatro eixos estruturantes: a articulação entre conhecimento específico/teórico e conhecimento pedagógico; a identidade docente e a formação cidadã; os saberes do professor; o projeto político pedagógico do curso. Neste artigo trataremos apenas do primeiro eixo, cujas questões estruturantes seguem abaixo:

a) como busca articular (relacionar) o conhecimento específico/teórico com a formação pedagógica dos futuros professores?

b) quem é o profissional bacharel que você pretende formar? E o licenciado? Como diferencia essa formação ao longo de sua disciplina?

Dos treze professores indicados pelos formandos, cinco são de disciplinas pedagógicas e oito de disciplinas específicas. Analisando o Currículo Lattes dos professores entrevistados, observamos que três possuem apenas mestrado (foram lembrados positivamente pelos alunos), os demais são doutores, destre os quais cinco possuem pós-doutorado. Dois professores não fizeram graduação em Ciências 
Biológicas, um deles sendo o mais citado.

De acordo com a análise da formação acadêmica dos professores, não há relação intrínseca entre o curso de graduação e o nível de pós-graduação e desempenho positivo ou negativo marcante, conforme opinião dos alunos. Entretanto, não cabe, a partir desses dados, a conclusão aligeirada de que a formação pouco importa para a qualidade do docente.

\section{Análise das entrevistas}

Analisando as entrevistas pudemos identificar a presença dos três fundamentos epistemológicos citados, sendo que um mesmo entrevistado apresentou ora fundamentos de uma epistemologia ora de outra, por isso evitamos ao máximo classificar seus dizeres. Optamos por falar em "tendências" epistemológicas, pois o discurso é movimento, uma mesma pessoa insere-se em diferentes contextos, apresenta diferentes dizeres, há trânsito entre as epistemologias referenciadas. Há, portanto, o cuidado quanto ao não estabelecimento de uma tipologia, de modo a gerar categorias estanques, o que reduziria a análise.

\subsection{A transmissão de saberes}

O processo de ensino-aprendizagem é entendido pela maioria dos professores de disciplinas específicas (seis professores, do total de oito) e por um professor de disciplina pedagógica numa concepção de "transmissão de saberes". Esses docentes entendem que contribuem para a formação do futuro professor por meio da transmissão de conhecimentos biológicos da área específica de sua disciplina aos seus alunos e, no aspecto pedagógico, tal contribuição se dá pelo seu exemplo, isto é, pela imitação de suas práticas.

Esses professores não demonstram "intencionalidade" na contribuição para a formação pedagógica desse licenciado, esse lugar é ocupado pelo exemplo, como expressa o Professor A no fragmento abaixo. As aulas desse formador são orientadas a partir da reprodução de procedimentos que julga adequados, conforme suas palavras: 
Eu parto do seguinte princípio: eu procuro oferecer aquilo que eu gostei de receber quando eu era aluno [...] Então, eu sei que existem procedimentos que me agradam, me agradavam como aluno e procedimentos que não me agradam, não me agradavam. Então procuro aplicar isso em aula. Se isso poderá ser de utilidade para os meus alunos, futuros professores, ótimo, mas eu não faço deliberadamente para isso, porque eu não tenho a formação pedagógica que eu sei que é necessária para orientá-los. [...] Eu não busco porque eu não me sinto habilitado para isto. O que eu faço, se vier o resultado, ótimo. [...] eu creio que isso cabe às disciplinas da área de formação pedagógica, uma formação que eu não tenho. (PROFESSOR A)

Percebe-se que suas aulas são orientadas sem um referencial externo, ele reproduz procedimentos que o agradam e nega aqueles que não o agradaram por meio de uma reflexão restrita à questão metodológica e pessoal, ficando a cargo do exemplo e da reprodução desse exemplo a formação pedagógica para si e para seus alunos. Aqui, apenas o saber experiencial (prático) é manifestado, apesar de o entrevistado reconhecer a importância da dimensão pedagógica que compõe essa formação, ele afirma ser esta responsabilidade dos professores da área educacional. Ou seja, prepondera em seu discurso a nítida separação entre o conteúdo do ensino e a forma de ensinar.

A falta de formação pedagógica destacada pelo Professor A é um ponto comum no discurso desses docentes, também apontada pelos professores B, C, D, L e M, como o motivo pelo qual eles não contemplam tal formação em suas disciplinas, conforme pode ser observado no fragmento abaixo.

Eu acho que não cabe a mim, na minha disciplina, eu não tenho nem formação para isso. Eu acho que a diferença básica entre bacharel e licenciado é dada em outras disciplinas, como as disciplinas de Psicologia, disciplina de Didática. Embora eu não tenha tido isso na minha formação, eu acho que para o professor é importante. A minha formação é bacharelado, eu não tenho licenciatura. (PROFESSOR C)

Esse docente reforça a separação entre os saberes específicos e pedagógicos, entre a licenciatura e o bacharelado, afirmando não apresentar como alvo de sua preocupação a formação pedagógica dos futuros professores, pois essa formação não seria de sua responsabilidade. Dessa forma, delega ao seu modelo de atuação docente, ou seja, seu exemplo de ser professor, a dimensão pedagógica da formação de seus 
alunos licenciandos. Essa ausência de formação pedagógica apontada por esses professores coloca em destaque a questão da pedagogia universitária, da necessidade de formação contínua para esse professor formador e do envolvimento institucional para que ela de fato ocorra.

Concomitante à ausência de formação pedagógica, há o preenchimento dessa lacuna com a pesquisa, ficando a atividade de ensino secundarizada e a dimensão de formador de professores é atenuada de tal modo que ele não se reconhece como detentor dessa função. Fato que aponta para a não regulamentação da formação de professores para o Ensino Superior no Brasil, não há um curso específico, como acontece na educação básica; bastam os cursos de pós-graduação.

Numa perspectiva semelhante à transmissão de conhecimento específico e reprodução de práticas que contribuem para legitimar a dicotomia entre saberes da área das ciências da natureza e da ciência educacional, o professor M aponta que,

Na verdade, a minha formação é mais de pesquisador e o que eu percebo é que muitas vezes, com essa formação de pesquisador, quando você passa o conhecimento de uma forma que você passa o pensamento científico, acho que isso de alguma forma contribui para a formação, além de pesquisadores, de professores também. Porque essa transmissão de uma linha científica é importante para ensinar. [...] Eu não tenho necessariamente, não tenho ainda, uma preocupação de formar professor, não é uma preocupação específica. (PROFESSOR M)

Esse docente identifica-se como pesquisador, ficando os saberes pedagógicos e a formação docente fora de suas preocupações prioritárias. Essa identificação com a pesquisa é fruto de sua própria formação. Em outro momento da entrevista ele afirma: "eu recebi essa formação durante a pós-graduação; é importante produzir, publicar, fazer pesquisa de ponta, são os meus ensinamentos" (PROFESSOR M).

Esse discurso está marcado pela epistemologia da atividade teórica, em que se enfatiza o conhecimento científico específico da disciplina, destacando-se a epistemologia da ciência. Entretanto, quando questionado sobre o papel do professor na formação do aluno, seu posicionamento é diferente, defendendo que o professor deve ser um orientador, um facilitador do processo de aprendizado de seus alunos, 
que devem ser ativos nesse processo.

Eu penso muito, porque às vezes na aula expositiva eu sinto que eu estou lá me desgastando, tentando passar o conhecimento e dependendo tem gente dormindo, está cansado, tudo bem, e aí você vê as pessoas pegam passivamente o conhecimento e eu acho que não é por aí, tem que despertar, prioridade, tem que olhar no livro, estudar, tem que de alguma forma conseguir despertar esse interesse para o aluno ir atrás das coisas $e$, às vezes, não dar aula expositiva você estimula mais o aluno a fazer isso. (PROFESSOR M)

Esse espaço de contradição no discurso desse professor, entre a transmissão de conhecimento (que ele percebe improdutiva) e a atividade do aluno, seria um espaço possível de mudança, mas que esbarra numa prática historicamente aceita e legitimada no meio acadêmico. Ele reconhece as limitações, mas também afirma que permanece nela.

O discurso do Professor J apresenta uma perspectiva instrumental da atividade docente e de hierarquização entre pesquisa e docência, com valorização da primeira.

A gente procura passar esse conhecimento, todo o conteúdo da matéria de forma que o aluno consiga absorver aquele conteúdo, mas de forma que o que ele absorva, ele possa passar depois na futura profissão dele como professor. [...] esse ano nós trabalhamos com a confecção de um manual da disciplina para avaliar como os alunos absorviam esse conhecimento para poder depois repassar e se de fato aquilo que a gente estava falando em sala de aula estava sendo absorvido de forma correta, porque muitos dos alunos da biologia eles vão trabalhar com Licenciatura. Então a gente não pode pensar só que o aluno vai ser o pesquisador, ele vai também trabalhar com alunos. Então, a nossa função dentro da universidade é também formar, capacitar esse aluno para esse tipo de atividade (PROFESSOR J).

Percebe-se, nesses discursos, a valorização de um currículo, cujo conhecimento está estruturado em disciplinas que não se comunicam, de tal modo a reforçar a separação entre os saberes específicos e pedagógicos, entre a licenciatura e o bacharelado, numa concepção individualista do saber fazer docente. Essa dicotomia é reflexo e é refletida na dissociação entre pesquisa e ensino, assumindo compromisso com a pesquisa, enquanto o ensino é entendido como complemento às atividades de pesquisador e restrito à reprodução do ensino de sua própria formação, por meio de uma metodologia cristalizada de aula expositiva com base 
na transmissão do conhecimento. Ou seja, a metodologia científica, tão cara à formação do futuro pesquisador, não é traduzida na metodologia de ensino utilizada por esses docentes.

Essa dicotomia reflete e é refletida nas epistemologias que fundamentam a concepção de formação docente desses professores. Observa-se que há um conflito entre a formação específica na área das Ciências Biológicas e a formação pedagógica, que são duas dimensões inseparáveis para um professor, mas que se encontram divididas nas falas dos entrevistados devido a essa lógica dual. Essa é também uma dicotomia epistemológica da concepção de formação docente, em que para a formação nos conhecimentos específicos biológicos se defende a transmissão de saberes, numa perspectiva epistemológica que se alinha à atividade teórica. Para a formação nos conhecimentos do campo educacional, valoriza-se o saber experiencial com destaque para o exemplo dos professores e a repetição dos bons exemplos, numa perspectiva pragmática de formação docente, ou seja, marcada pela atividade prática.

\subsection{A formação na prática}

Para quatro professores entrevistados (três docentes de disciplinas pedagógicas e um de disciplina específica), a formação inicial tem como eixo central a prática docente, que é aqui entendida apenas na dimensão da atividade do professor em sala de aula; desconsideramse outras dimensões de sua prática, ou seja, a prática como aquisição de experiências e reprodução de modelos. A contribuição teórica para a formação é restrita à teoria das disciplinas específicas das Ciências Biológicas, característica da formação para o bacharelado. Abaixo, o depoimento do Professor G, que aponta para essa perspectiva.

Eu acho que a gente se torna professor sendo professor. Eu acho que a formação que a gente tem dentro das licenciaturas dá um embasamento razoável para que a gente desempenhe o papel do professor, mas eu acho que ela não é a linha mestra do ser professor de qualquer um. [...] Sempre que eu tenho oportunidade de discutir isso com pessoas, via de regra, o que eu encontro é: as pessoas vão se formando baseadas no exemplo de professores que elas tiveram ao longo da vida. Então elas vão vendo e vão 
falando igual aquele eu quero ser, igual aquele outro eu não quero ser. Então ela pega o modelo pedagógico, o modelo que um segue do jeito de ser, mais do que estuda e tenta entender porque aquele é daquele jeito e porque o outro não é. A fundamentação teórica dentro da pedagogia, para mim, tem um caráter secundário na formação dos professores enquanto professores, educadores. (PROFESSOR G)

Numa perspectiva semelhante, o Professor E afirma que "O aluno tem que ter a prática para poder desenvolver" (grifo nosso); a prática aqui entendida como o elemento central e articulador do processo formativo, o silenciamento quanto à teoria educacional demonstra o papel de complemento em função da prática que ela assume. Nesse processo, o futuro professor também se constitui por meio do exemplo de antigos professores, sendo a imitação uma importante forma de aquisição de metodologias de ensino, a partir da reprodução de práticas de antigos professores.

O Professor H reconhece o valor da teoria, mas a prática é tomada como eixo central em sua visão de formação docente, defendendo a formação do professor reflexivo em um processo de ação-reflexão-ação; a teoria da educação aparece de forma pragmática, a serviço da prática. Ele destaca a prática como seu eixo central na formação do licenciando: "Apesar dele ter pouco tempo ali (campo de estágio), ele se depara com a realidade da escola, uma série de limites e possibilidades que ele foi percebendo ao longo da sua formação, que é lá na prática" (PROFESSOR H).

O Professor I (responsável por uma disciplina pedagógica) defende a formação do futuro professor por meio de pesquisa, sendo que esta se relaciona intrinsecamente com a prática docente em busca de inovação; a pesquisa como meio de resolução de problemas da prática. A pesquisa, nesse caso, não se relaciona com um método científico, nem com uma fundamentação teórica que a sustente, é entendida a partir e em função da prática docente.

A gente sabe que isso hoje é fundamental que o professor desenvolva uma prática, mas que a prática não fique estagnada dentro de um modelo. [...] Primeiro ler, fazer a leitura de um ambiente, como as pessoas estão envolvidas nesse processo e então procurar um jeito novo. [...] A pesquisa é tida como o momento criativo do professor, algo que ele pode fazer com o estudo, com conversa com os colegas, com novas vivências. É isso que ele pode fazer no seu cotidiano de vida e de sala de aula. (PROFESSOR I) 
Esse docente apresenta avanços, em relação aos outros entrevistados, na concepção de formação ao contemplar a pesquisa como elemento articulador do processo formativo, porém essa concepção apresenta limites impostos pela própria prática, ao ser tomada como fim em si mesma da atividade docente.

Nessa perspectiva, a formação docente é entendida como algo prioritariamente de natureza prática, deixando-se que se desenvolvam formas conceituais de modo a reduzir o conhecimento à "praticidade" dos contextos. A teoria do campo da educação e da pedagogia é secundarizada, limitando a análise e a compreensão dos contextos em que oorrem os processos educativos. Com isso, restringe-se a possibilidade característica da teoria de se colocar como forma de "lançar a dúvida de forma sistematizada, de modo que o entendimento que se tem da realidade educacional esteja alicerçado em argumentos conceituais" (PACHECO, 2011, p. 280).

Portanto, sem a teoria como guia da ação docente, a prática dá-se num processo tautológico de reflexão a partir da prática e na prática, atuando para a manutenção do status quo. Nessa perspectiva pragmática, como na epistemologia da atividade teórica discutida acima, a docência é entendida numa perspectiva instrumental, individualmente concebida, em que se mantêm as dicotomias entre produção de saber e sua reprodução, pesquisa e ensino, teoria e prática.

\subsection{Modelos alternativos para a formação docente}

Três docentes entrevistados compreendem a formação de professores a partir de concepções que rompem com o modelo historicamente constituído de formação baseado na transmissão-recepção de conhecimentos e de dicotomização e hierarquização entre teoria e prática. Desses professores, dois deles são responsáveis por disciplinas pedagógicas e um é responsável por disciplina específica.

O Professor F entende que o biólogo, seja bacharel ou licenciado, é um "pesquisador-educador" e um "educador-pesquisador"; portanto, não se pode separar a produção e a transmissão do conhecimento, além 
de considerar a educação como área de produção de conhecimento científico. Esse docente também destaca a importância de articular os conhecimentos específicos e pedagógicos. Em sua disciplina, busca contribuir com essa formação adotando uma abordagem que valoriza as relações e, também, por intermédio do seu próprio exemplo. “Tento dar para ele (aluno) a maior quantidade possível de elementos para que ele consiga entender que aquele organismo interage com $n$ fatores, e isso tudo servindo como exemplo para que um outro que ele encontre, também procure fazer vários tipos de associações" (PROFESSOR F).

Esse docente apresenta um posicionamento oposto à ideia de aluno como receptor do conhecimento. Entende que o processo educativo vai além da memorização e que o conhecimento deva fazer sentido para o aluno. Em seu discurso, o docente valoriza a seleção curricular, preocupase em estabelecer relações entre o conhecimento e o contexto mais amplo e a sociedade da informação em que vivemos.

Porque a gente sabe também que éo seguinte: em sala você não consegue encher, o estudante não é um balde que você enche de coisas. Mas você vai mostrar o caminho de investigação, de busca de mais informação. Você vai conseguir fornecer, na melhor das hipóteses alguns filtros, para ele começar a selecionar as informações, informações que vão realmente fazer sentido dentro do conjunto. (PROFESSOR F)

Essa visão de aluno tem reflexo na posição que o docente ocupa no processo educativo; ele retira o professor do eixo central, pois deve se preocupar com o aluno, uma vez que a ação educativa é uma relação social entre professor e aluno, que demanda o envolvimento de ambas as partes.

O Professor K, por sua vez, afirma trabalhar de forma a fundamentar a prática docente na teoria educacional, buscando na história da educação entender o que é a escola e como ela está inserida no mundo contemporâneo, inclusive, procurando desconstruir a ideia naturalizada da escola como transmissora de conhecimento apenas ou como reprodutora de desigualdades e preconceitos, a fim de pensar algumas possibilidades da escola na contemporaneidade a partir de uma abordagem antropológica. Busca fazer conexões entre a escola e a sociedade, relacionando teoria da educação à prática vivenciada na instituição escolar. 
Quando eu penso na formação do futuro professor e da futura professora, eu quero imaginar que esse professor ou essa professora tenha um arsenal de instrumentos que são textos, discussões, teorias, enfim, um arsenal de processos que vão dos textos, das aulas, dos filmes que a gente assiste, porque eu trabalho bastante com cinema, enfim, pensando nesse arsenal de possibilidades para que esse futuro professor ou professora possa se formar ao longo da sua carreira, da sua vida. [...]. Agora, o interesse, na verdade, é que essa disciplina possa afetar. Possa alterar maneiras de pensar, desconstruir preconceitos, desconstruir naturalizações que são inúmeras dentro do pensamento educacional. Então, é nesse sentido que eu penso os objetivos dessa disciplina. (PROFESSOR K)

É interessante nesse discurso a maneira com a qual esse docente compreende a finalidade de sua disciplina, ressaltando a desconstrução de preconceitos e naturalizações no campo da educação. Assim, defende a necessidade de se olhar para a educação para além da perspectiva de transmissão-recepção de conhecimentos disciplinarizados, para que, a partir da teoria educacional, possa olhar para a realidade e vislumbrar possibilidades de se fazer diferente; para que possa olhar para a escola como uma construção humana, não como um fato dado.

Vamos duvidar dessa ideia de real, que aquilo que você vai enxergar ali é a escola real, está ali, pronto, acabou. Não, vamos lançar um olhar mais antropológico para essa escola, mas, a partir dessa aproximação do olhar antropológico para a escola, os alunos começam a perceber quais são as relações que estão envolvidas no cotidiano dessa escola, desde a própria organização da escola até chegarmos na aula. (PROFESSOR K)

Esse professor busca aproximar os futuros professores da perspectiva das Ciências Humanas e afirma sentir muita resistência por parte deles, advindos de um curso que tem as Ciências Naturais como sua característica mais marcante e como concepção de ciência. Para ele, esses alunos vêm com uma maneira de entender a ciência a partir das Ciências Naturais e são confrontados com uma maneira diferente de se fazer ciência nas Ciências Humanas e Sociais. Essa forma de pesquisa não faz sentido para a maioria desses alunos, pois a própria estrutura do curso, de modo geral, privilegia essa dicotomia, no caso da licenciatura, entre saberes específicos e saberes pedagógicos.

Sobre essa dicotomia, o Professor L defende a necessidade de se romper com a lógica do curso de Ciências Biológicas, em que primeiro 
o estudante tem contato com as disciplinas específicas da Biologia, se formando como bacharel para, ao final do curso, ter a formação pedagógica. Para ele, muitos alunos veem a docência como uma segunda opção de atuação, de forma que: "alguns com a intenção de ter uma outra opção de emprego, quer dizer, assim que formado eu tenho a possibilidade também de trabalhar como professor, mas eu acredito que a maioria deles têm essa ideia de querer ser professor." (PROFESSOR L).

Diante desse contexto, esse professor busca desenvolver sua prática a partir desse aluno e situá-lo no contexto da escola pública brasileira. Também se preocupa com que seus alunos:

entendam que teoria é teoria e prática é prática. A relação dos dois é que dá a continuidade daquilo que ele pretende fazer na escola. Não é só a experiência que assegura uma boa formação do professor, mas também não é só a teoria. É a experiência articulada com aquilo que está sendo construído enquanto teoria pela universidade. (PROFESSOR L)

Por esse fragmento da entrevista, percebe-se que esse docente não entende o professor da educação básica como produtor de conhecimento pedagógico, pois a produção do conhecimento é apontada como tarefa acadêmica, da universidade. Aqui, novamente nos deparamos com um espaço de contradição do discurso de um professor que reconhece a educação como possibilidade de transformação social, porém separa a produção e a transmissão do conhecimento.

Apesar dessa divisão entre produção e transmissão de saberes, ele defende a articulação entre experiência e teoria, na relação entre "o que ele vai ter do contex to da escola, visitar a escola, conhecer a realidade dos professores, observar algumas aulas, tudo isso não acontece se ele não tiver noção de uma realidade teórica". Vemos que a articulação entre teoria e prática é um elemento central para a organização de sua disciplina, apresentando um espaço de contradição e, por isso mesmo, de possibilidade de superação.

Os professores F, K e L apresentam visões da formação docente que se direcionam à epistemologia da práxis, ao considerar a união entre teoria e prática, entre pesquisa e ensino, e também ao pensar o processo educativo inserido numa realidade mais ampla e produzido pelo homem. Nesses discursos não há valorização nem da prática, nem da teoria, mas sim o entendimento da necessidade de articulação desses polos no processo 
formativo, possibilitando a superação de limites impostos à formação docente face ao modelo formativo historicamente adotado.

Nesses discursos vislumbramos possibilidades de mudança e de superação. Percebemos que um discurso fatalista sobre a formação docente não é suficiente para compreender a realidade, que se mostra complexa e contraditória e, por isso mesmo, passível de transformação. Os discursos desses professores mostram que a educação não é estática, havendo espaço para se pensar diferente e para construir outra concepção de formar professores. Mas, percebemos que esses discursos se dão isoladamente, havendo convergência de ideias entre eles. Reforçamos a necessidade da universidade tomar para si a responsabilidade de formar professores, superando a dicotomia entre licenciatura e bacharelado, entre ensino e pesquisa, como esses professores denunciam as dificuldades que tal dualidade impõem à formação docente.

\section{Algumas considerações}

Quanto às tendências epistemológicas da formação docente, concluise que no curso investigado a epistemologia da atividade teórica é a dominante dentre os docentes entrevistados responsáveis por disciplinas específicas. Para os professores de disciplinas pedagógicas, observamos que a tendência mais influente é a epistemologia da atividade prática.

Esses professores se colocam na posição do aluno, têm preocupações em estimular a atenção do discente, despertar seu interesse, fazer com que ele tenha vontade de aprender e trabalhar aquele conteúdo, buscam motivar o aluno para que ele se mobilize em aprender um dado conhecimento. Trata-se de valorizar a interação professor-aluno, o professor conseguir tocar o estudante, sensibilizá-lo, fazer com que ele queira aprender. A relação humana é eleita como mais fundamental na ação docente para esses professores e está centrada, a nosso ver, na importância de desenvolver estratégias de ensino que atuem como moldes para a formação pedagógica de seus alunos. Seus exemplos participam da formação dos futuros professores como modelos pedagógicos a serem imitados em seus procedimentos docentes futuros. O modo de agir dos 
formadores atua então, como um "currículo oculto" da metodologia do ensino. Nessa perspectiva, mais da metade dos entrevistados não apresenta "intencionalidade" explícita na formação pedagógica do futuro professor, ou seja, não assumem o seu papel de formadores de professores, que se dá de modo passivo por meio de sua maneira de agir, e ignoram o contexto e as dimensões profissionais no seu ensino.

A formação docente tendo a imitação de modelos como fundamento apresenta algumas limitações, pois transpõe modos de agir em situações para as quais podem não são adequadas. Aqui, há o agravante de se tratar de diferentes níveis de ensino, a transposição de exemplos do ensino superior para a educação básica. O pressuposto dessa concepção é que a realidade do ensino é imutável, assim como os alunos. Ainda, o conceito de bom professor é polissêmico, passível de interpretações diferentes e mesmo divergentes. Como essa concepção se baseia na imitação e repetição, gera o conformismo, é conservadora de hábitos, ideias, valores, comportamentos pessoais e sociais pela cultura institucional dominante (PIMENTA; LIMA, 2004).

Esses professores têm as suas identidades constituídas com base nos saberes da experiência, construídos no exercício profissional mediante o ensino de saberes específicos das suas áreas de conhecimento, sejam das Ciências Naturais ou Ciências Humanas. Coloca-se, portanto, o desafio de desenvolver condições que possibilitem a análise crítica desses saberes da experiência construídos nas práticas, confrontandoos com as produções teóricas da educação, da pedagogia e da didática, entendendo a docência como campo específico de intervenção na prática social e sempre em contexto.

Em sua maioria, os entrevistados não reconhecem as disciplinas específicas como espaço de formação docente, elas são associadas à formação quanto ao "conteúdo". Essa ausência de relação entre as disciplinas da área de referência e aquelas voltadas especificamente para o tratamento das questões educacionais também foi observada nas ementas de 31 cursos de licenciatura em Ciências Biológicas em pesquisa realizada por Gatti e Nunes (2008). Portanto, percebemos que seja nos discursos seja nos ementários a superação da dicotomia entre 
conhecimento específico e pedagógico proposta pelos documentos promulgados recentemente não é concretizada, sendo essa uma questão que permanece latente no campo da formação docente.

Percebemos dois modelos formativos nesses discursos, ambos dentro de uma mesma lógica de instrumentalização. O primeiro diz respeito à ideia de formação baseada na transmissão-recepção de saberes, que fundamenta a concepção de formação da maioria dos professores de disciplinas de conteúdos biológicos, dentro de uma perspectiva teórica academicista de formação, que desconsidera a relação do seu conteúdo com a formação pedagógica dos futuros professores. O segundo relaciona-se com a formação pedagógica na prática, sendo essa prática a reprodução de modelos e técnicas bem-sucedidos no ato de ensinar. Ou seja, a formação biológica segue um modelo e a formação pedagógica, outro; porém em ambos a concepção de ensinar é tecnicista, desconsiderando-se a realidade na qual o ensino ocorre e cobra sentido.

Outro fator que corrobora essa análise é que nos discursos desses professores há, de modo geral, o silenciamento da escola como instituição e do significado social do ser professor, o que nos leva a crer que em suas disciplinas não são estabelecidos os nexos entre os conteúdos que desenvolvem e a realidade em que se dá o ensino. De modo que ficam alguns questionamentos: o que significa ser professor para esses professores? Que professor se quer formar e para qual sociedade? Qual a função social da educação?

Contudo, três professores mencionam a importância da pesquisa em educação e da teoria educacional como base para uma plena atividade docente. Esses professores apontam para possibilidades de formação docente que rompem com o modelo historicamente constituído, mostrando caminhos alternativos na direção de uma formação na práxis.

Não é o caso, em absoluto, de culpabilizar os professores formadores pelas mazelas do ensino, mas sim de reconhecer e valorizar a importância da profissão docente no Ensino Superior, em especial, a formação de futuros professores. Nesse sentido, é essencial que as instituições universitárias discutam os processos de construção de identidade docente e os de profissionalização. A universidade é um lócus privilegiado para o 
desenvolvimento de ações que possibilitem o rompimento com o modelo historicamente constituído de formação, permitindo novos olhares para esse processo. Percebemos nos discursos de alguns professores formadores essa disposição para repensar a formação docente, apontando para possibilidades que rompem com as prescrições e mostram que é possível uma formação comprometida com a justiça social, desde que o desafio seja assumido coletiva e institucionalmente.

\subsection{Implicações para a formação docente}

Assumimos e defendemos a perspectiva de uma formação fundamentada na práxis como forma de constituir professores capazes de contribuir para a análise social e política que é necessária para vislumbrar e, então, desafiar as estruturas que continuam impedindo a construção coletiva de uma sociedade em que os filhos de todos tenham acesso aos meios e às condições que os ajudem na condução de uma vida produtiva e recompensadora (ZEICHNER, 2008).

A formação deve ser fundamentada na práxis, porém ela não é práxis profissional, pois o curso não é lugar da prática profissional (que o aluno exercerá quando for profissional), a formação é atividade teórica de aproximação com a prática, tomada como preocupação sistemática no currículo (PIMENTA, 2010b).

Todavia, compreender a formação docente de modo instrumental implica em uma série de consequências pedagógicas e sociais. Nessa perspectiva, os futuros professores são preparados para executar técnicas de ensino, de modo a não discutir mais profundamente as finalidades do ensino, e assim, tornam-se executores de reformas políticas. Não estamos negando a necessidade de instrumentalização do professor para sua profissão, mas ressaltamos a necessidade de articulação entre o como fazer e as intencionalidades pedagógicas. Estas, por sua vez, na lógica vigente de ação tendem a estar compromissadas com a manutenção das desigualdades sociais e se objetivam por meio de medidas reguladoras, que são pouco questionadas pelos seus agentes. Quanto ao formador desse professor, não estaria também ele exercendo 
esse papel de executor?

De modo geral, as entrevistas apontam para a descrição de um curso construído sobre o fundamento da instrumentalização do ser professor, seja pela teoria, seja pela prática. Observa-se nítida separação entre esses polos. Esse modelo é explicitado por Kuenzer (2004, p. 2).

Os conhecimentos, requisito para a execução de atividades práticas, nos cursos médios e superiores voltados para a formação profissional, eram ensinados na sua dimensão teórica durante a maior parte do curso; o espaço para supostamente aprender a prática, o fazer, ocorria ao final do percurso formativo, através do estágio, ficando a articulação entre teoria e prática por conta do aluno.

A inserção no espaço laboral, a partir dos estágios ou do emprego, contemplava a dimensão tácita do conhecimento, supervalorizando o saber fazer sobre o conhecimento científico e a parte sobre o todo, de modo a tornar corriqueira a denúncia dos alunos sobre a inutilidade da formação teórica, reproduzida pelos profissionais de recursos humanos que privilegiavam a experiência como critério de seleção (KUENZER, 2004).

Essa forma de se compreender uma profissão se mostra ainda verdadeira nos discursos investigados. Teoria e prática estão epistemologicamente separadas nessa formação, no próprio conceito de formação de professores. Como consequência, tem-se a dicotomização entre ensino e pesquisa, licenciatura e bacharelado, disciplinas pedagógicas e específicas. Essas dualidades, fruto da separação entre teoria e prática, apresenta como consequência a docência entendida como um "fazer", conforme os discursos da maioria dos professores entrevistados.

Essa separação entre teoria e prática, como valorização da segunda para a formação docente, pode reforçar a ilusão de que há prática sem teoria ou de uma teoria desvinculada da prática. Essa dualidade nega a práxis e, inclusive, nega a teoria e nega a prática, pois ambas só podem existir na dialética entre a teoria - teorização de uma prática - e a prática - finalidade e critério de verdade da teoria.

Nesse contexto, a teoria é vista até mesmo de forma prejudicial à prática profissional, pela ideia de que ela não permite um adequado enfrentamento da prática laboral. A prática é entendida como autossuficiente e tomada em sentido utilitário, reduzida à atividade e aos 
modos de fazer no discurso da maioria dos sujeitos entrevistados quando se trata da formação inicial do professor ao afirmarem, por exemplo, que a formação do professor se dá na prática e demandam pela maior necessidade de prática ao longo do curso. Nesse caso, a teoria passa a ser substituída pelo senso comum, que é o sentido da prática, e a ela não se opõe (KUENZER, 2004). Não estamos negando o valor da prática no processo de formação do professor, porém entendemos a prática sempre acompanhada de uma teoria que a fundamenta e que a guia, e garante a autonomia ao professor.

A constatação da permanência e perpetuação da cisão entre teoria e prática na formação de professores demonstra a necessidade de continuidade dos trabalhos na área, em direção a possibilidades de superação desse modelo. 


\section{Referências}

BRASIL. Resolução CNE/CP 02/2002, de 19 de fevereiro de 2002. Institui a duração e a carga horária dos cursos de licenciatura, de graduação plena, de formação de professores da Educação Básica em nível superior. Disponível em: <http:/ / portal.mec.gov.br/cne/ arquivos/pdf/CP022002.pdf>. Acesso em: 06 maio 2012.

CONTRERAS, J. A autonomia de professores. Tradução de Sandra Trabucco Valenzuela. São Paulo: Cortez, 2002.

FREIRE, P. Educação como prática da liberdade. 14. ed. rev. atual. Rio de Janeiro: Paz e Terra, 2011.

GATTI, B. A.; NUNES, M. M. R. (Org.) Formação de professores para o ensino fundamental: estudo de currículos das licenciaturas em pedagogia, língua portuguesa, matemática e ciências biológicas. São Paulo: FCC/DPE, 2008.

GÓMEZ, A. P. O pensamento prático do professor: A formação do professor como profissional reflexivo. In: NÓVOA, A. (Org.). Os professores e a sua formação. 1. ed. Lisboa: Dom Quixote, 1992. p. 93-114.

KUENZER, A. Z. A relação entre a teoria e a prática em face das mudanças ocorridas no mundo do trabalho. In: CONFERÊNCIA DE ABERTURA DO V SEMINÁRIO PROGRAD. Temática: Estágio Curriculares: Significado na Educação Profissional, PUC Minas, Belo Horizonte, 3 e 4 de dezembro, 2004.

KUENZER, A. Z. Da dualidade assumida à dualidade negada: o discurso da flexibilização justifica a inclusão excludente. Educação $\mathcal{E}$ Sociedade, Campinas, v. 28, n. 100, p. 1.153-1.178, out. 2007.

KUENZER, A. Z. Currículo, trabalho e profissionalização 
docente. In: COLÓQUIO LUSO-BRASILEIRO SOBRE QUESTÕES CURRICULARES E VIII COLÓQUIO SOBRE QUESTÕES

CURRICULARES, 4., 2008. Universidade Federal de Santa Catarina, Florianópolis, 2008.

LIBÂNEO, J. C. Reflexividade e formação de professores: outra oscilação do pensamento pedagógico? In: PIMENTA, S. G. e GHEDIN, E. (Orgs.). Professor reflexivo no Brasil: gênese e crítica de um conceito. 6. ed. São Paulo: Cortez, 2010. p. 53-79.

MINAYO, M.C.S. (Org.). Pesquisa social: teoria, método e criatividade. 29. ed. Petrópolis, RJ: Vozes, 2010.

PACHECO, J. A. Currículo: entre teorias e métodos. In: COLÓQUIO LUSO-BRASILEIRO SOBRE QUESTÕES CURRICULARES, Florianópolis: UFSC, 2011.

PIMENTA, S. G. Professor reflexivo: construindo uma crítica. In: PIMENTA, S. G.; GHEDIN, E (orgs.) Professor Reflexivo no Brasil: gênese e crítica de um conceito. 6. ed. São Paulo: Cortez, 2010a. p. 17-52.

PIMENTA, S. G. O estágio na formação de professores: unidade teoria e prática? 9. ed. São Paulo: Cortez, 2010b.

PIMENTA, S. G.; LIMA, M. S. L. Estágio e docência. 2. ed. revisão técnica José Cerchi Fusari. São Paulo: Cortez, 2004.

VÁZQUEZ, A. S. Filosofia da práxis. Rio de Janeiro: Paz e Terra, 1977.

ZEICHNER, K. Uma análise crítica sobre a "reflexão" como conceito estruturante na formação docente. Educação $\mathcal{E}$ Sociedade, v. 29, n. 103, p. 535-554, 2008.

Recebido em 08/04/2014 Aprovado em 25/11/2014 